\title{
Avaliação da qualidade óssea mediante parâmetros morfométricos, bioquímicos e biomecânicos em frangos de corte
}

\author{
Anderson de Almeida Barbosa ${ }^{1}$, George Henrique Kling de Moraes ${ }^{1}$, Robledo de Almeida \\ Torres $^{2}$, Denise Torres da Cruz Reis ${ }^{1}$, Conrado de Souza Rodrigues ${ }^{3}$, Elisa Sialino Müller ${ }^{1}$
}

${ }^{1}$ Departamento de Bioquímica e Biologia Molecular, Universidade Federal de Viçosa.

2 Departamento de Zootecnia, Universidade Federal de Viçosa.

${ }^{3}$ Departamento Acadêmico de Engenharia Civil, Centro Federal de Educação Tecnológica de Minas Gerais.

RESUMO - Objetivou-se determinar aspectos bioquímicos, morfométricos e biomecânicos dos fêmures de frangos de corte. Utilizaram-se 600 pintos de 1 dia de idade, machos e fêmeas, de três híbridos (Hb1 e Hb2 - UFV e Hb3 - comercial). As aves foram alimentadas à vontade com rações para as fases inicial ( 1 a 21 dias), de crescimento (22 a 35 dias) e final (36 a 42 dias). O delineamento experimental foi inteiramente casualizado em esquema fatorial $3 \times 2$, composto de três cruzamentos e dois sexos, cinco repetições e dez aves por unidade experimental (boxe). Avaliaram-se no fêmur o peso, o comprimento, a área da seção transversal, o momento de inércia, a carga máxima na flexão, a tenacidade e resistência à flexão, o conteúdo de proteínas colagenosas e não-colagenosas e o peso vivo das aves. Aos 21, 28, 35 e 42 dias de idade, foram amostrados aleatoriamente um macho e uma fêmea por boxe, num total de cinco boxes por híbrido. Entre híbridos, Hb3 apresentou maior peso vivo em todas as idades e, entre sexos, os machos foram mais pesados. A força máxima na flexão foi maior para os machos e, para os híbridos, $\mathrm{Hb} 3$ foi maior que $\mathrm{Hb} 1$ e igual a $\mathrm{Hb} 2$ aos 42 dias. O piores resultados de tenacidade e resistência à flexão foram observados nos machos híbridos Hb2, que não diferiram dos Hb3 quanto à resistência à flexão aos 42 dias nem quanto à tenacidade medida em todas as idades, o que caracteriza baixa qualidade óssea dos híbridos Hb3 e machos. Devem-se considerar aspectos biomecânicos como tenacidade e resistência à flexão para corrigir e evitar o aparecimento das desordens ósseas provenientes do aumento de peso em frangos de corte.

Palavras-chave: fêmur, híbridos, minerais, sexo

\section{Evaluation of bony quality through biochemical, morphometrics and biomechanical aspects of broilers}

\begin{abstract}
The objective of the experiment was to determine the biochemical, morphometrics and biomechanical aspects of femur bones of broilers. It was used six hundred male and female broilers at one day of age from three different lines (Hb1 and Hb2 - UFV and Hb3 - commercial). They were fed ad libitum on starter (1 to 21 days), grower (22 to 35 days) and finisher (36 to 42 days) rations. The experimental design was completely randomized, in a factorial arrangement $3 \times 2$ (three lines and two sexes) with 5 replicates and 10 birds per experimental unit (box). The weight, length, cross-sectional area, moment of inertia, maximum load, modulus of elasticity, bending strength, collagenous and non collagenous proteins and body weight of the broilers were evaluated in the femur. At 21, 28, 35 and 42 days of age, one male and one female of each line were randomly selected per box, in a total of five boxes per line. Among lines, Hb3 presented higher superior body weight in all ages, and among sexes, the males were heavier. The strength of maximum load was higher for the males and lines HB3 was higher than HB1and equal to HB2 at 42 days of age. The worst results of elasticity and bending strength at 42 days of age were observed in males from line HB2, which did not differ from HB3 regarded to bending at 42 days of age and to elasticity measured in all ages, which characterizes low bone quality of the males and line HB3. Biomechanical aspects of femurs bones, as modulus of elasticity and bending strength, to correct and avoid bone damages of broilers due to their heavier weight.
\end{abstract}

Key Words: femur, hybrids, mineral, sex

\section{Introdução}

As deformidades ósseas têm causado prejuízos cada vez maiores à produção industrial de frangos de corte.
Existem duas categorias de problemas mais gerais: a discondroplasia tibial, que acomete os frangos na fase inicial do crescimento, e os problemas estruturais, que levam as deformidades e distorções dos ossos longos,

Recebido em 29/8/2008 e aprovado em 15/4/2009.

Correspondências devem ser enviadas para: aab62@hotmail.com 
sobretudo na fase final de crescimento (Lilburn, 1994). O osso está intimamente relacionado ao crescimento do animal e passa por adaptações constantes na sua constituição, podendo estar hipertrofiado quando é mais exigido, ou atrofiado quando em desuso. Alguns fatores, como sexo (Rath et al., 1999), idade (Yalçin et al., 2001), taxa de crescimento (Leterrier, 1998), cruzamentos comerciais, nutrição (Edwards, 2000; Borgatti et al., 2009) e temperatura ambiente (Bruno et al., 2007), têm sido associados às diferenças na qualidade do osso. O aumento desproporcional no peso dos animais, principalmente no músculo do peito, em decorrência da seleção genética pode gerar distúrbios esqueléticos-biomecânicos (Lilburn, 1994) e afetar diferentemente machos e fêmeas, determinando a prevalência de certas deformidades (Kestin et al., 1992; Lilburn, 1994; Rose et al., 1996). Parece que a velocidade de mineralização e outros aspectos de desenvolvimento do fêmur ocorrem mais lentamente que na tíbia, pois os ossos dos membros amadurecem mais cedo, dependendo da distância do corpo (Kwakkel et al., 1998). Assim, o fêmur pode ser o principal elo entre o rápido ganho de peso e os problemas de pernas em frangos (Lilburn, 1994). Portanto, objetivou-se com este trabalho avaliar propriedades bioquímicas, físicas e biomecânicas dos fêmures de frangos de corte de três híbridos comerciais e entre sexos.

\section{Material e Métodos}

O experimento foi realizado na Granja de Melhoramento de Aves do Departamento de Zootecnia da Universidade Federal de Viçosa (UFV) utilizando-se 600 pintos de 1 dia de idade, constituindo três grupos de 200 aves (dois com híbridos (Hb1 e Hb2) e um com de marca comercial (Hb3)) de ambos os sexos.

Os híbridos foram alojados separadamente depois de identificados, vacinados contra Marek e Bouba Aviária. Foi adotado delineamento experimental inteiramente casualizado, em esquema fatorial $3 \times 2$ (três grupos genéticos e dois sexos) com 5 repetições para cada idade de 21, 28, 35 e 42 dias, de modo que a unidade experimental foi representada por um boxe, cada um com cinco machos e cinco fêmeas com densidade de $0,225 \mathrm{~m}^{2}$ para cada ave. Adotou-se um programa de luz contínua, com 24 horas de luz (natural + artificial) e fornecimento, à vontade, de água e ração adequada para cada fase: 1 a 21 dias (ração inicial), 22 a 35 dias (de crescimento) e 36 a 42 dias (final) (Tabela 1).

Aos 21, 28, 35 e 42 dias de idade, um macho e uma fêmea por box, num total de cinco boxes por grupo genético, foram pesados, sacrificados por deslocamento cervical e tiveram os fêmures removidos. Em seguida os fêmures foram descarnados, pesados e seus comprimentos medidos com paquímetro de precisão de $0,02 \mathrm{~mm}$, e armazenados a $-20^{\circ} \mathrm{C}$

Tabela 1 - Composição percentual das rações experimentais

\begin{tabular}{lccc}
\hline Ingrediente (\%) & Inicial (1 a 21 dias) & Crescimento (22 a 35 dias) & Final (36 a 42 dias) \\
\hline Farelo de soja & 38,90 & 33,60 & 28,31 \\
Milho & 53,48 & 59,07 & 65,24 \\
Óleo de soja & 3,10 & 1,60 & 3,10 \\
Fosfato bicálcico & 2,64 & 0,89 & 0,80 \\
Calcário calcítico & 0,83 & 0,210 & 0,140 \\
DL-metionina (99\%) & 0,240 & 0,080 & - \\
L-lisina & 0,100 & 0,39 & 0,39 \\
Sal comum & 0,39 & 0,06 & 0,03 \\
Cloreto de colina (60\%) & 0,10 & 0,10 & 0,10 \\
Mistura vitamínica ${ }^{2}$ & 0,10 & 0,05 & 0,05 \\
Mistura mineral & 0,05 & 0,05 & - \\
Salomicina sódica (12\%) & 0,06 & 0,01 & 0,01 \\
Butil hidroxi tolueno & 0,01 & & 18,48 \\
Composição calculada & & 3066,00 & 0,88 \\
Energia metabolizável (kcal/g) & & 20,37 & 0,44 \\
Proteína bruta (\%) & 2960,00 & 0,93 & 0,967 \\
Cálcio (\%) & 22,30 & 0,46 & 0,434 \\
Fósforo disponível (\%) & 1,11 & 1,167 & 0,529 \\
Lisina (\%) & 0,60 & 1,324 & \\
Metionina (\%) & 0,582 & & \\
\hline
\end{tabular}

${ }^{1}$ Níveis de garantia por quilo do produto: vit. A - 10.000.000 UI; vit. D3 - 2.000.000 UI; vit. E - 30.000 UI; vit. B1 - 2,0 g; vit. B6 - 4,0 g; ácido pantotênico - 12,0 g;

biotina - 0,10 g; vit. K3 - 3,0 g; ácido fólico - 1,0 g; ácido nicotínico - 50,0 g; vit. B12 - 15.000 mcg; selênio - 0,25 g; e veículo q.s.p - 1.000 g.

2 Níveis de garantia por quilo do produto: manganês - 16,0 g; ferro - 100,0 g; zinco - 100,0 g; cobre - 20,0 g; cobalto - 2,0 g; iodo - 2,0 g; veículo q.s.p. - 1.000 g. 
para posteriores análises. Os fêmures esquerdos foram descongelados até a temperatura ambiente para a realização dos ensaios mecânicos. As propriedades mecânicas foram determinadas por ensaios de flexão em três pontos, com os ossos apoiados em suas extremidades. A carga mecânica (F) foi aplicada no meio da diáfise a uma velocidade constante de $10 \mathrm{~mm} / \mathrm{min}$, conforme especificado pela Sociedade Americana de Engenharia Agrícola (ASAE S459, 1998). A distância entre os dois pontos de apoio foi alterada de acordo com a idade das aves, atingindo $30 \mathrm{~mm}$ aos 21 e 40 $\mathrm{mm}$ aos 28 , 35 e 42 dias de idade devido ao crescimento longitudinal dos ossos. Foi utilizada máquina universal de ensaios mecânicos da marca EMIC acoplada a um computador que registrou continuamente os dados referentes à carga mecânica aplicada e à deflexão correspondente $(\delta)$ em pares de pontos $(\mathrm{F}, \delta)$, constituindo a curva de carregamento, para se estabelecerem os parâmetros mecânicos (Figura 1).

Após os ensaios de carga, os cálculos dos parâmetros geométricos, necessários à determinação das propriedades mecânicas, foram realizados com base nas medidas dos diâmetros internos e externos da seção transversal rompida de cada osso. Para tanto, a seção transversal dos fêmures foi assumida como uma elipse oca (ASAE S459, 1998). A área da seção transversal está representada na equação 1 e o momento de inércia (MI) na equação 2 . O momento de inércia considera tanto as dimensões quanto a forma da seção transversal e representa a resistência da amostra à deflexão (Turner \& Burr, 1993). Para calcular a inércia de uma elipse oca, consideram-se B e b os diâmetros externo e interno correspondentes à largura do osso e, D e d os diâmetros externo e interno, respectivamente, correspondentes à altura da seção transversal, considerando sua posição no ensaio de flexão (Figura 2).

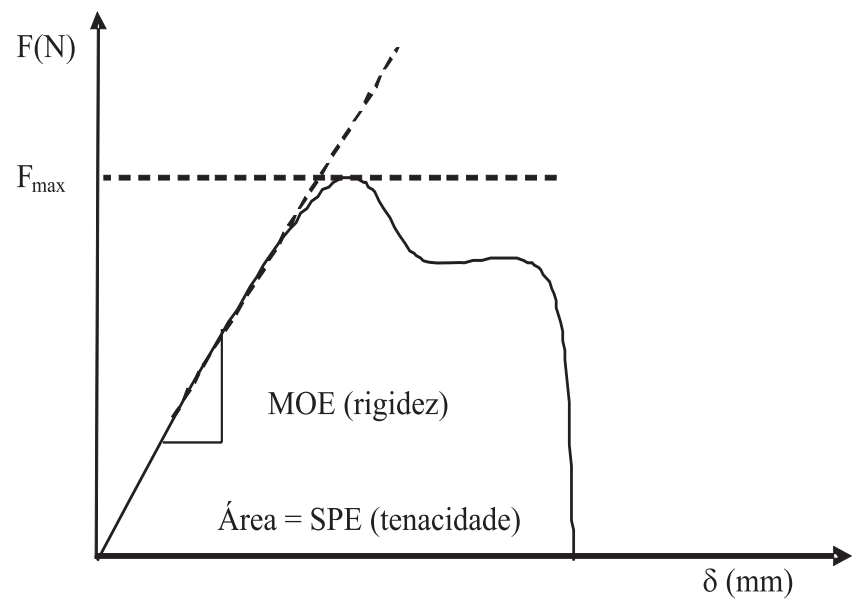

Figura 1 - Modelo geral da curva de carregamento de fêmures.

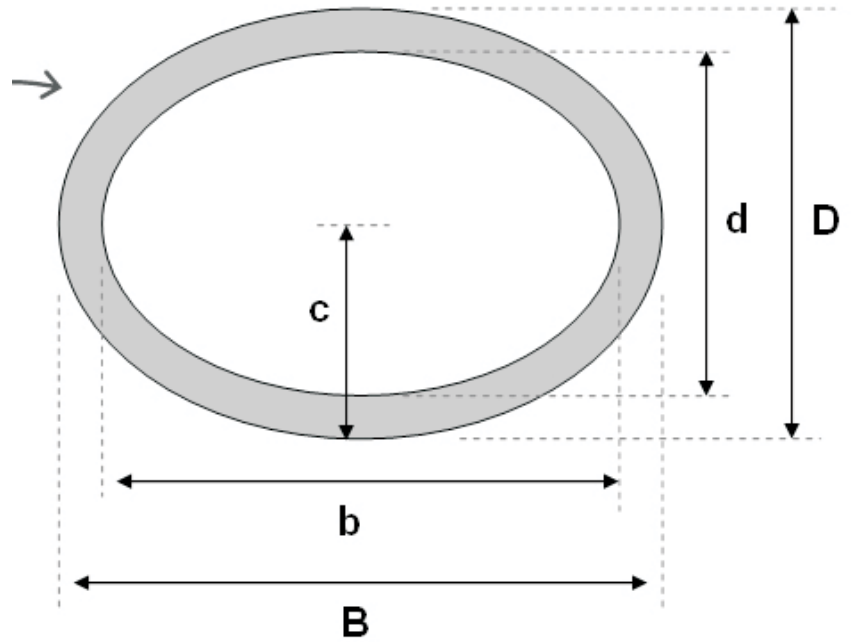

Figura 2 - Representação esquemática da seção transversal dos fêmures como uma elipse oca.

$$
\begin{aligned}
& \mathrm{AST}=\pi(\mathrm{BD}-\mathrm{bd}) \\
& \mathrm{MI}=0,049\left[\left(\mathrm{BD}^{3}\right)-\left(\mathrm{bd}^{3}\right)\right]
\end{aligned}
$$

A resistência à flexão ou módulo de ruptura (MOR) expressa a propriedade intrínseca do material ósseo, independentemente do tamanho e da sua forma. Para ensaios de flexão em três pontos, o MOR é calculado segundo a equação 3, em que $\mathrm{F}_{\max }$ é a carga máxima suportada pela amostra, $L$ a distância entre os dois apoios, c é a metade da altura da seção transversal e MI é o momento de inércia.

$$
M O R=\frac{F_{\max } \cdot L . c}{4 . M I}
$$

A quantidade de energia necessária para causar a fratura do osso na flexão é denominada tenacidade na flexão (SPE) e foi calculada pela área sob a curva (incluindo região elástica e plástica). Essa propriedade é muito importante em biomecânica porque um osso mais tenaz pode ser mais resistente à fratura mesmo que a carga máxima que ele resista seja menor (Turner \& Burr, 1993).

Os fêmures utilizados para o teste de flexão foram cortados longitudinalmente, removendo-se a medula óssea com jatos de água destilada e deionizada. A seguir foram desengordurados com éter de petróleo, em aparelho Soxhlet, por 12 horas, para determinação das concentrações das proteínas não-colagenosas e de proteínas colagenosas. A seguir, os fêmures foram desmineralizados extensivamente com solução de sal dissódico de EDTA (ácido etilenodiamino tetracético) 0,5 M epH 8,2, (Hauschka \& Gallop, 1977) para a extração das proteínas nãocolagenosas que contêm as Gla-proteínas ósseas com pesos moleculares menores que $10 \mathrm{kd}$. O fim da extração foi confirmado com o ácido oxálico, que permite identificar a 
desmineralização completa. Após a extração, os volumes foram ajustados para $20 \mathrm{~mL}$ para as idades de 21 e 28 dias, e $40 \mathrm{~mL}$ para as idades de 35 e 42 dias. As proteínas foram quantificadas na solução de Bradford (1976), utilizando-se albumina sérica bovina como padrão.

Depois de desengordurados e desmineralizados, os ossos foram lavados exaustivamente com água destilada deionizada para a extração do excesso de EDTA. Para determinação do teor de proteínas colagenosas, utilizou-se o método de Berthelot modificado por Pesemk \& Nielsen, de acordo com Silva et al. (2001), que estima o nitrogênio total, com o emprego de fenol cristal, nitroprussiato de sódio e hipoclorito de sódio. Como padrão usou-se sulfato de amônio anidro. O teor de proteínas não-colagenosas foi obtido multiplicando-se o teor de nitrogênio pelo fator 6,25.

A análise estatística dos resultados experimentais foi realizada empregando-se o Sistema para Análises Estatísticas e Genéticas - UFV (SAEG, 2000) usando-se o teste Tukey $(\mathrm{P} \leq 0,05)$ para comparação das médias.

\section{Resultados e Discussão}

Como não houve interação entre cruzamentos e sexos, ambos foram avaliados separadamente (Tabela 2). Em todas as idades, os híbridos $\mathrm{Hb} 3$ foram mais pesados $(\mathrm{P}<0,05)$ que os da UFV ( Hb1, Hb2), que não diferiram entre si em nenhuma idade. Já entre os sexos, machos foram maiores $(\mathrm{P}<0,05)$ em todas as idades, caracterizando o mesmo efeito do dimorfismo sexual encontrado por Yalçin et al. (2001). O dimorfismo sexual pode estar relacionado aos níveis de hormônios, como GH, IGF-I e androstenediona em machos após 28 dias de idade, e também pode variar dentre os cruzamentos (Rose et al., 1996).

O híbrido comercial apresentou maior peso $(\mathrm{P}<0,05)$ dos ossos aos 21, 28 e 35 dias de idade, em relação a Hb1 e $\mathrm{Hb} 2$, que só diferiram na idade de 28 dias, de modo que os $\mathrm{Hb} 2$ foram os menos pesados. Para a idade de 42 dias, os Hb3 não diferiu ( $\mathrm{P}>0,05)$ dos Hb1 e Hb2, caracterizando uma redução do ganho do peso ósseo. Também para o

Tabela 2 - Peso vivo e influência da linhagem e do sexo nas características morfológicas e biomecânicas dos fêmures

\begin{tabular}{|c|c|c|c|c|c|c|}
\hline \multirow[t]{2}{*}{ Característica } & \multirow[t]{2}{*}{ Idade (dias) } & \multicolumn{3}{|c|}{ Híbrido } & \multicolumn{2}{|c|}{ Sexo } \\
\hline & & $\mathrm{Hb} 1$ & $\mathrm{Hb} 2$ & Hb3 & Macho & Fêmea \\
\hline \multirow[t]{4}{*}{ Peso vivo (g) } & 21 & $669,80 \mathrm{~b}$ & $674,30 \mathrm{~b}$ & $862,30 a$ & $786,47 \mathrm{a}$ & $684,47 b$ \\
\hline & 28 & $1115,20 b$ & $1087,20 b$ & $1419,60 \mathrm{a}$ & $1346,40 a$ & $1068,27 b$ \\
\hline & 35 & $1320,40 b$ & $1357,00 \mathrm{~b}$ & $1676,60 \mathrm{a}$ & $1602,67 a$ & $1300,00 \mathrm{~b}$ \\
\hline & 42 & $1884,20 b$ & $1878,80 \mathrm{~b}$ & $2534,70 a$ & $2310,40 a$ & $1888,07 b$ \\
\hline \multirow[t]{4}{*}{ Peso do osso (g) } & 21 & $2,57 b$ & $2,55 b$ & $3,51 \mathrm{a}$ & 3,23a & $2,52 b$ \\
\hline & 28 & $5,25 b$ & $4,27 \mathrm{c}$ & $6,72 \mathrm{a}$ & $6,31 \mathrm{a}$ & $4,52 b$ \\
\hline & 35 & $7,55 b$ & $8,41 b$ & $10,15 a$ & $9,87 a$ & $7,54 b$ \\
\hline & 42 & $10,12 \mathrm{a}$ & $10,19 a$ & $11,22 \mathrm{a}$ & $12,14 \mathrm{a}$ & $8,89 b$ \\
\hline \multirow[t]{4}{*}{ Comprimento do osso (cm) } & 21 & $4,94 b$ & $4,97 b$ & 5,13a & $5,10 a$ & $4,94 b$ \\
\hline & 28 & $5,91 b$ & $5,85 b$ & $6,17 \mathrm{a}$ & 6,14 a & $5,82 b$ \\
\hline & 35 & $6,62 b$ & $6,84 \mathrm{ab}$ & $6,93 a$ & 6,99a & $6,60 \mathrm{~b}$ \\
\hline & 42 & $7,38 \mathrm{a}$ & $7,42 \mathrm{a}$ & $7,49 a$ & $7,64 \mathrm{a}$ & $7,22 b$ \\
\hline \multirow[t]{4}{*}{ Área da seção transversal $\left(\mathrm{cm}^{2}\right)$} & 21 & $0,2439 a$ & $0,2378 a$ & $0,2386 a$ & $0,2625 a$ & $0,2177 b$ \\
\hline & 28 & $0,2771 b$ & $0,3364 a$ & $0,3371 \mathrm{a}$ & $0,3445 a$ & $0,2892 b$ \\
\hline & 35 & $0,3165 a$ & $0,3138 a$ & $0,3723 a$ & $0,3607 \mathrm{a}$ & $0,3078 b$ \\
\hline & 42 & $0,4329 a$ & $0,3969 a$ & $0,4574 a$ & $0,5040 \mathrm{a}$ & $0,3542 b$ \\
\hline \multirow[t]{4}{*}{ Força máxima (N) } & 21 & $210,11 \mathrm{a}$ & $189,93 a$ & $207,23 a$ & $232,40 a$ & $172,44 b$ \\
\hline & 28 & $183,98 b$ & $202,51 \mathrm{ab}$ & $225,29 a$ & $218,45 a$ & $189,40 \mathrm{~b}$ \\
\hline & 35 & $179,12 b$ & $202,65 b$ & $252,03 a$ & $211,79 a$ & $21074 a$ \\
\hline & 42 & 209,21b & $247,45 a b$ & $282,05 a$ & $272,84 a$ & $219,63 b$ \\
\hline \multirow[t]{4}{*}{ Resistência à flexão (MPa) } & 21 & $57,74 a$ & $52,52 \mathrm{a}$ & $59,42 \mathrm{a}$ & $59,49 a$ & $53,63 a$ \\
\hline & 28 & $47,17 \mathrm{a}$ & $41,61 \mathrm{a}$ & $40,34 \mathrm{a}$ & 39,63a & $46,45 a$ \\
\hline & 35 & $35,89 a$ & $42,58 a$ & $34,29 a$ & $34,50 b$ & $40,66 a$ \\
\hline & 42 & $29,70 b$ & 39,39a & $34,01 \mathrm{ab}$ & $30,17 b$ & $38,56 a$ \\
\hline \multirow[t]{4}{*}{ Tenacidade à flexão (KJ/m²) } & 21 & $12,27 \mathrm{a}$ & $11,51 \mathrm{a}$ & $12,28 \mathrm{a}$ & $12,70 \mathrm{a}$ & $11,35 \mathrm{a}$ \\
\hline & 28 & $11,97 \mathrm{a}$ & $10,50 \mathrm{a}$ & $9,63 a$ & $9,20 \mathrm{a}$ & $12,20 \mathrm{a}$ \\
\hline & 35 & $11,27 \mathrm{a}$ & $13,47 a$ & $11,04 \mathrm{a}$ & $11,23 a$ & $12,63 a$ \\
\hline & 42 & $13,17 \mathrm{a}$ & $12,88 \mathrm{a}$ & $12,45 a$ & $11,60 \mathrm{~b}$ & $14,06 \mathrm{a}$ \\
\hline \multirow[t]{4}{*}{ Momento de inércia $\times 10^{-10}\left(\mathrm{~m}^{4}\right)$} & 21 & $0,96 a$ & $0,98 \mathrm{a}$ & $0,95 a$ & $1,11 \mathrm{a}$ & $0,83 a$ \\
\hline & 28 & $1,64 \mathrm{a}$ & $1,98 \mathrm{a}$ & $2,04 \mathrm{a}$ & $2,20 \mathrm{a}$ & $1,57 \mathrm{a}$ \\
\hline & 35 & $2,25 a$ & $2,27 \mathrm{a}$ & 3,03a & $2,98 \mathrm{a}$ & $2,06 \mathrm{a}$ \\
\hline & 42 & $3,98 a$ & $3,26 a$ & $4,18 \mathrm{a}$ & $4,88 \mathrm{a}$ & $2,68 b$ \\
\hline
\end{tabular}

Médias seguidas de mesma letra minúscula nas linhas não diferem $(\mathrm{P}>0,05)$ entre si, para híbridos e para sexo, pelo teste Tukey. 
comprimento do osso, o híbrido comercial teve comprimento maior $(\mathrm{P}<0,05)$ apenas aos 21 e 28 dias de idade. Aos 42 dias de idade, não ocorreram diferenças ( $\mathrm{P}>0,05$ ) entre os híbridos Hb3, Hb2 e Hb1 e, aos 35 dias de idade, Hb3 foi maior que Hb1, que não diferiu de Hb2. Leterrier \& Nys (1992), quando trabalharam com cruzamentos diferentes para ganho de peso, encontraram que animais de crescimento rápido tiveram pesos e dimensões maiores para a tíbia, mas, quando corrigiram para a mesma unidade de PV, verificaram que não houve diferença entre cruzamentos e que o aumento do osso depende do peso do animal. Entretanto, parece que a velocidade de crescimento não interfere nessas propriedades ósseas, uma vez que Leterrier et al. (1998) trabalharam com mesma linhagem restringindo a energia para um grupo de aves e não observaram diferença entre grupos de mesmo peso vivo. Contudo, os animais que cresceram mais lentamente tiveram menor incidência de problemas de pernas. Bruno et al. (2000) encontraram valores menores para comprimento e diâmetro, mas não para o peso dos fêmures quando submeteram frangos de corte a uma restrição alimentar de $40 \%$ da alimentação à vontade. Williams et al. (2000) encontraram o mesmo resultado deste trabalho, ou seja, animais com maior crescimento demonstraram redução no comprimento do osso em relação ao peso vivo. Todavia, alegaram que isso pode ser mais uma forma de adaptação biomecânica ao aumento de PV, pois menor tamanho do fêmur implica menor momento de flexão sobre esse osso, o que constitui uma vantagem para os animais.

A área da seção transversal e o momento de inércia não diferiram ( $\mathrm{P}>0,05)$ aos 21, 35 e 42 dias entre os híbridos (Tabela 2). Aos 28 dias, os Hb1 apresentaram área menor $(\mathrm{P}<0,05)$ que a dos $\mathrm{Hb} 2$ e Hb3, que não diferiram entre si. A área da seção transversal e o momento de inércia aumentaram com a idade nos três híbridos, acompanhando a curva de ganho de peso dos animais. Williams et al. (2004) sugeriram que, à medida que o animal cresce, a forma geométrica do osso se torna menos circular, podendo não deixar transparecer possíveis diferenças quanto à área da seção transversal e o momento da inércia. Muitas variáveis ósseas não são afetadas pela origem genética, mas existe forte correlação entre o PV e o volume do osso e a área da seção transversal, independentemente da origem genética (Leterrier et al., 1998). A seleção genética é capaz de modificar o diâmetro ósseo somente quando características ósseas são usadas como parâmetro de seleção, por exemplo, a espessura da canela em perus (Nestor et al., 1987). Leterrier \& Nys (1992) encontraram maior área da seção transversal para animais mais pesados, embora tenham observado que o aumento da seção transversal foi consequência do aumento do volume do osso e não de sua massa óssea determinada por sua densidade ou seu conteúdo em cinzas. O mesmo foi observado por Williams et al. (2000), que encontraram maior área da seção transversal e momento da inércia para animais que cresceram mais rápido, mas também observaram que não houve melhora na qualidade da matriz óssea. Mesmo assim, alegaram que os animais foram capazes de adequar as dimensões ósseas ao ritmo de crescimento e compensar o maior peso imposto sobre os ossos, o que é um bom fator. Neste trabalho, o híbrido comercial não foi capaz de diferenciar estas propriedades ósseas, mesmo tendo crescido mais rápido, o que caracteriza deficiência desta linhagem.

Nos machos, peso do osso, comprimento do osso e área da seção transversal foram significativamente maiores que nas fêmeas em todas as idades. O momento de inércia, no entanto, foi igual para machos e fêmeas em todas as idades, exceto aos 42 dias de idade (Tabela 2). Yalçin et al. (1998) não encontraram efeito do sexo sobre o comprimento, o peso e a espessura dos ossos, mas encontraram correlação significativa entre o PV e peso, comprimento e espessura óssea. Embora o dimorfismo sexual esteja presente desde o nascimento, para o comprimento ósseo existe um gene (Dw/dw) que pode determinar encurtamento de ossos longos em machos. Rose et al. (1996) confirmaram esta observação por não terem observado diferenças no peso, volume e comprimento ósseo até os 26 dias de idade, mas foram bastante evidentes aos 42 dias. O mesmo foi observado por Bond et al. (1991), que não notaram diferenças no tamanho das tíbias em 7 semanas de idade, mas observaram diferentes nos animais adultos. Entretanto, para a AST e área da córtex óssea, Rose et al. (1996) confirmaram o dimorfismo sexual desde o nascimento.

A força máxima na flexão $\left(\mathrm{F}_{\text {máx }}\right)$ aos 21 dias não diferiu $(\mathrm{P}>0,05)$ entre os cruzamentos. Aos 28 dias, Hb2 foi igual a Hb3 e Hb1 e o Hb1 menor que Hb3 (Tabela 2). Aos 35 dias $\mathrm{Hb} 3$ foi maior que Hb1 e Hb2 e aos 42 dias de idade Hb3 foi maior que Hb1, mas não diferiu de Hb2. Yalçin et al. (1998) não encontraram correlação entre níveis proteicos da dieta e habilidade de caminhar com propriedades ósseas, mas encontraram correlação positiva entre $F_{\text {máx }}$ e peso e comprimento do osso. Também não encontraram correlação entre o PV e $\mathrm{F}_{\text {máx }}$, sugerindo que o peso e tamanho do osso poderiam ser usados para prever $\mathrm{F}_{\text {máx }}$, mas o $\mathrm{PV}$ não foi o parâmetro adequado. Talvez esses autores não tenham encontrado correlação entre $F_{\text {máx }}$ e PV por alguma debilidade na linhagem estudada, visto que esta correlação está bem definida (Wiliams et al., 2004). Todavia, o aumento, por si só, da $\mathrm{F}_{\text {máx }}$ não implica melhor qualidade do osso, pois esta 
variável está diretamente relacionada à geometria óssea, como comprovado pela área da seção transversal e o momento de inércia. Quando se excluiu a influência destas variáveis geométricas pela avaliação da resistência à flexão, que é o melhor parâmetro para avaliar a qualidade intrínseca do material ósseo, não ocorreram diferenças significativas entre os cruzamentos. Somente aos 42 dias, Hb2 foi maior que $\mathrm{Hb} 1$ e não diferiu de Hb3. Isso sugere que a qualidade dos ossos de Hb3 foi comprometida, já que esse híbrido apresentou maior peso vivo. Este comprometimento do material ósseo pode estar relacionado à alta taxa de síntese e absorção nos ossos em desenvolvimento de animais de crescimento rápido para o ajuste do seu tamanho e de sua geometria ao maior peso imposto (Williams et al., 2004). Isso explica, em parte, o aparecimento de deformidades ósseas em animais mais pesados em mesma idade e com mesmas propriedades biomecânicas (Leterrier \& Nys, 1992).

Em todas as idades, os três híbridos não diferiram $(\mathrm{P}>0,05)$ quanto à tenacidade na flexão (SPE) (Tabela 2). Entre sexos, machos foram significativamente piores apenas aos 42 dias, o que indica que suportam menor carga nesta idade caracterizando pior qualidade óssea. As propriedades mecânicas ósseas são determinadas pelas quantidades relativas dos três maiores constituintes ósseos (minerais, água e material orgânico, representado principalmente pelo colágeno tipo I), pela qualidade desses elementos e pelo modo como estão arranjados na matriz óssea (Currey, 2003).

Neste trabalho não houve diferença significativa para a proteína colagenosa nas idades entre os híbridos aos 21 e 42 dias, aos 28 dias Hb3 foi menor que Hb1 e Hb2 que não diferiram entre si. Aos 35 dias, $\mathrm{Hb} 2$ foi menor que Hb1 e Hb3, que também não diferiram entre si. Entre sexos, somente aos 21 dias, as fêmeas foram menores que machos. (Tabela 3).

Aos 28 dias Hb3 não diferiu de $\mathrm{Hb} 1$ e foi menor que $\mathrm{Hb} 2$ e, aos 35 dias de idade, Hb2 foi menor que Hb1 que não diferiu de Hb3. Apesar de as proteínas colagenosas terem aumentado com a idade nos três híbridos dos 21 aos 28 dias, as tenacidade na flexão para todos os híbridos em todas as idades foram praticamente iguais, contrariamente ao que se esperava, pois, com o aumento nas concentrações de colágeno, esperava-se aumento desta variável. Rath et al. (1999) demonstraram que não só a quantidade do colágeno pode interferir na resistência óssea mas também as ligações cruzadas entre as cadeias de colágenos à medida que os animais vão ficando mais velhos. Neste trabalho, como os animais ainda eram muito jovens, provavelmente não houve tempo hábil para a formação destas ligações cruzadas, pois a maturidade óssea é atingida após 25 semanas de idade (Rath et al., 1999). Outros fatores, como porosidade e proporção de água do osso, podem piorar a qualidade óssea (Rose et al., 1996) e interferir na tenacidade na flexão, pois, como já mencionado, a forma como as fibras de colágeno estão dispostas e as proporções entre minerais, água e material proteico interferem decisivamente nas propriedades mecânicas dos ossos (Currey, 2003).

As proteínas não-colagenosas não apresentaram diferenças significativas tanto para os cruzamentos quanto entre os sexos (Tabela 3). Somente aos 35 dias Hb1 foi menor $(\mathrm{P}<0,05)$ que Hb2 e Hb3. O que se notou claramente, tanto para cruzamentos quanto para sexos, foi uma diminuição acentuada dos 21 aos 28 dias e dos 35 aos 42 dias de idade. Geralmente os ossos longos em aves têm rápido crescimento até os 18 dias e mineralização até os 11 dias após a eclosão (Williams et al., 2000). Esse período não foi estudado neste trabalho, mas a redução das concentrações das proteínas não-colagenosas após os 21 dias comprovaram redução na atividade metabólica dos ossos, pois essas proteínas são responsáveis como enucleadores para formação dos cristais de hidroxiapatita ou, no caso da osteocalcina, como responsável pela taxia dos osteoclastos no processo de reabsorção óssea (Roach, 1994). Isso explica, em parte, a piora da qualidade óssea aos 42 dias expressas pela resistência à flexão.

Tabela 3 - Proteínas colagenosas e não-colagenosas dos fêmures de frangos de corte machos e fêmeas no período de 21 a 42 dias de idade

\begin{tabular}{|c|c|c|c|c|c|c|}
\hline \multirow[t]{2}{*}{ Variável } & \multirow[t]{2}{*}{ Idade (dias) } & \multicolumn{3}{|c|}{ Híbridos } & \multicolumn{2}{|c|}{ Sexo } \\
\hline & & Hb1 & $\mathrm{Hb} 2$ & $\mathrm{Hb} 3$ & Macho & Fêmea \\
\hline \multirow[t]{4}{*}{ Proteínas colagenosas (\%) } & 21 & $15,44 \mathrm{a}$ & $14,91 \mathrm{a}$ & $16,27 \mathrm{a}$ & $16,51 \mathrm{a}$ & $14,57 b$ \\
\hline & 28 & $27,08 \mathrm{ab}$ & $29,83 a$ & $23,21 b$ & $27,63 a$ & $25,78 a$ \\
\hline & 35 & $30,81 \mathrm{a}$ & $22,03 \mathrm{~b}$ & $30,47 a$ & $26,63 a$ & $28,91 \mathrm{a}$ \\
\hline & 42 & $30,20 a$ & $26,02 \mathrm{a}$ & $26,20 \mathrm{a}$ & $26,68 a$ & $28,26 a$ \\
\hline \multirow[t]{4}{*}{ Proteínas não-colagenosas (\%) } & 21 & $3,36 a$ & $4,30 \mathrm{a}$ & $3,97 a$ & $3,77 \mathrm{a}$ & $3,98 a$ \\
\hline & 28 & $1,55 \mathrm{a}$ & $1,46 \mathrm{a}$ & $1,21 \mathrm{a}$ & $1,37 \mathrm{a}$ & $1,45 a$ \\
\hline & 35 & $1,08 \mathrm{~b}$ & $1,75 \mathrm{a}$ & $1,37 a b$ & $1,28 \mathrm{a}$ & $1,52 \mathrm{a}$ \\
\hline & 42 & $0,63 a$ & $0,77 \mathrm{a}$ & $0,77 a$ & $0,72 \mathrm{a}$ & $0,77 a$ \\
\hline
\end{tabular}

Médias seguidas por uma mesma letra minúscula nas linhas não diferem $(\mathrm{P}>0,05)$ entre si para híbridos e para sexo pelo teste Tukey. 


\section{Conclusões}

A tenacidade e a resistência à flexão indicam a qualidade óssea e comprovam a pior qualidade óssea de híbridos HB3. Portanto, deve-se incluir estes aspectos biomecânicos nos programas de seleção genética, que expressam diretamente a qualidade do material ósseo e não somente os que caracterizam a força óssea, para corrigir e evitar o aparecimento das desordens ósseas provenientes do aumento de peso em frangos de corte.

\section{Agradecimentos}

Ao professor Ricardo Marius Della Lucia, por viabilizar os ensaios mecânicos e pelo apoio técnico; à CAPES e FAPEMIG, pelo apoio financeiro.

\section{Referências}

AMERICAN SOCIETY OF AGRICULTURAL ENGINEERS. ASAE Standard S459. Shear and three-point bending test of animal bone. St. Joseph: ASAE, 1998. p.581-583.

BOND, P.L.; SULLIVAN, T.W.; DOUGLAS, J.H. et al. Influence of age, sex and method of rearing on tíbia length and mineral deposition in broilers. Poultry Science, v.70, n.9, p.1936-1942, 1991.

BORGATTI, L.M.O.; VITTI, D.M.S.S.; OLIVEIRA, T.M. et al. Biodisponibilidade relativa de fósforo em ingredientes com baixo teor de fitato determinada com base na mineralização óssea de frangos de corte. Revista Brasileira de Zootecnia, v.38, n.10, p.1901-1906, 2009.

BRADFORD, M. A rapid and sensitive method for the quantitation of microgram quantitaties of protein utilizing the principle of protein-dye binding. Analytical Biochemistry, v.72, n.2, p.248-254, 1976

BRUNO, L.D.G.; FURLAN, R.L.; MALHEIROS, E.B. et al. Influence of early quantitative food restriction on long bone growth at different environmental temperatures in broiler chickens. British Poultry Science, v.41, p.389-394, 2000

BRUNO, L.D.G.; LUQUETTI, B.C.; FURLAN, R.L. et al. Influence of early qualitative feed restriction and environmental temperature on long bone development of broiler chickens. Journal of Thermal Biology, v.32, p.349-354, 2007.

CURREY, J.D. Role of collagen and other organics in the mechanical properties of bone. Osteoporos Int, v.14, n.5, p.29-36, 2003.

EDWARDS JR., H.M. Nutrition and skeletal problems in poultry. Poultry Science, v.79, n.7, p.1018-1023, 2000.

HAUSCHKA, P.V.; GALLOP, P.M. Purification and calcium binding properties of osteocalcin, the carboxyglutamate containing protein of bone. In: WASSERMAN, R.H. (Ed.) Calcium binding proteins and calcium function. Amsterdam: Elsevier, 1977. p.338-347.

KESTIN, S.C.; KNOWLES, T.G.; TINCH. A.E. et al. Prevalence of leg weakness in broiler chickens and its relationship with genotype. The Veterinary Record, v.131, n.9, p.190-194, 1992.

KWAKKEL, R.P.; HOF, G.; ZANDSTRA, T. et al. Diphasic allometric growth of some skeletal bones and the digestive tract in white leghorn pullets consuming ad libitum and restricted diets. Poultry Science, v.77, p.826-833, 1998.

LETERRIER, C.; NYS, Y. Composition, cortical structure and mechanical properties of chicken tibiotarsi: effect of growth rate. British Poultry Science, v.33, n.5, p.925-939, 1992.

LETERRIER, C.; ROSE, N.; CONSTANTIN, P. et al. Reducing growth rate of broiler chickens with a low energy diet does not improve cortical bone quality. British Poultry Science, v.39, n.1, p.24-30, 1998.

LILBURN, M.S. Skeletal growth of commercial poultry species. Poultry Science, v.73, n.6, p.897-903, 1994.

NESTOR, K.E.; BACON, W.L.; MOORHEAD, P.D. et al. Comparison of boné and muscle growth in turkey lines selected for increased body weight and increased shank width. Poultry Science, v.66, n.9, p.1421-1428, 1987.

RATH, N.C.; BALOG, J.M.; HUFF, G.R. et al. Comparative differences in the composition and biomechanical properties of tibia of seven- and seventy-two-week-old male and female broiler breeder chickens. Poultry Science, v.78, n.8, p.1232-1239, 1999.

ROACH, H.I. Why does bone matrix contain non-collagenous proteins? The possible roles of osteocalcin, osteopontin and bone sialoprotein in bone mineralization and resorption. Cell Biology International, v.18, n.6, p.617-628, 1994.

ROSE, N.; CONSTANTIN, P.; LETERRIER, C. Sex differences in bone growth of broiler chickens. Growth, Development and Aging, v.60, n.2, p.49-59, 1996.

SILVA, F.A.; MORAES, G.H.K.; RODRIGUES, A.C.P. et al. Efeitos do ácido L-glutâmico e da vitamina $\mathrm{D}_{3}$ no desempenho e nas anomalias ósseas de pintos de corte. Revista Brasileira de Zootecnia, v.30, n.6, p.2059-2066, 2001.

TURNER, C.H.; BURR, D.B. Basic biomechanical measurements of bone: A tutorial. Bone, v.14, n.4, p.595-608, 1993.

UNIVERSIDADE FEDERAL DE VIÇOSA - UFV. SAEG Sistema de análises estatísticas e genéticas. Versão 8.0 . Viçosa, MG: 2000. 150p.

WILLIAMS, B.; SOLOMON, S.; WADDINGTON, D. et al. Skeletal development in the meat type chicken. British Poultry Science, v.41, n.2, p.141-149, 2000.

WILLIAMS, B.; WADDINGTON, D.; MURRAY, D.H. et al. Bone strength during growth: influence of growth rate on cortical porosity and mineralization. Calcified Tissue International, v.74, n.3, p.236-245, 2004.

YALÇIN, S.; ÖZKAN, S.; COSKUNER, E. et al. Effects of strain, maternal age and sex on morphological characteristics and composition of tibial bone in broilers. British Poultry Science, v.42, n.2, p.184-190, 2001.

YALÇIN, S.; SETTAR, P.; DICLE, O. Influence of dietary protein and sex on walking ability and bone parameters of broilers. British Poultry Science, v.39, n.2, p.251-256, 1998. 